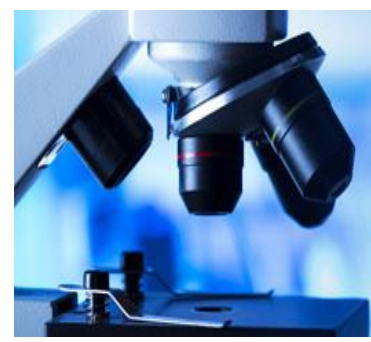

E-ISSN: 2707-4455 P-ISSN: 2707-4447 www.forensicpaper.com/ IJFM 2020; 2(1): 10-12

Received: 09-11-2019

Accepted: 12-12-2019

Dr. Vijaya Ranawana Department of Forensic medicine, Institute of Forensic Medicine \& Toxicology, Colombo, Sri Lanka
Corresponding Author: Dr. Vijaya Ranawana Department of Forensic medicine, Institute of Forensic Medicine \& Toxicology, Colombo, Sri Lanka

\section{Recording of iatrogenic artefacts during autopsy}

\section{Dr. Vijaya Ranawana}

DOI: https://doi.org/10.33545/27074447.2020.v2.i1a.18
Abstract

Background: Iatrogenic injury is defined as unintended or unnecessary harm or suffering arising from any aspect of healthcare management. The present study was conducted to assess iatrogenic artefacts during autopsy.

Materials \& methods: The present study was conducted on 152 dead bodies of both genders. Post mortem examination of the case was carried out. Various iatrogenic cutaneous artefacts were recorded Results: Out of 152 patients, males were 82 and females were 70. Common artefacts were iv line mark in 4, defibrillator burn mark in 12, abdominal drainage in 3, intercoastal drainage in 2, CVP line mark in 17, venesection in 10, fasciotomy wound in 2 and tracheostomy wound in 3 cases. The difference was significant $(P<0.05)$

Conclusion: Authors found that common artefacts were iv line mark, defibrillator burn mark, abdominal drainage, intercoastal drainage, CVP line mark, venesection, fasciotomy wound and tracheostomy wound.

Keywords: Artefacts, intercoastal drainage, wound

\section{Introduction}

Artefact is defined as any change caused or feature introduced in the natural state of the body that is likely to be misinterpreted at autopsy. Iatrogenic injury is defined as unintended or unnecessary harm or suffering arising from any aspect of healthcare management [1]. Artefacts arising from these injuries is called as iatrogenic artefacts. In this 21 st century, due to advancement in medical care most of the bodies examined at autopsy have some attempt of cardiopulmonary resuscitation (CPR) before pronouncement of death. An unending variety of therapeutic procedures are performed on patient for the treatment of illness or injury. Sometimes it is inevitable that even with the best of care, unintended consequences may occur during these procedures. Even therapeutically unimportant injuries can be important for forensic pathologists since they have to distinguish iatrogenic injuries from those caused by accident or assault ${ }^{[2]}$.

The common thread of all artefacts lies in the importance of experience in their recognition ${ }^{[3]}$. With the advent of advance life support system and rapid strides being made in the field of surgery and the ever improving interventional techniques newer features may be introduced into the body which runs a high risk of being misinterpreted to be a medicolegally significant finding. For such conclusions may have disastrous effect, particularly in an instances where homicide is a possibility, as it may make a difference between freedom and imprisonment of life or death of someone ${ }^{[4]}$. The present study was conducted to assess iatrogenic artefacts during autopsy.

\section{Materials \& methods}

The present study was conducted in the department of Forensic Medicine. It comprised of 152 dead bodies of both genders. Ethical clearance was taken prior to the study.

General information such as name, age, gender etc. was recorded. Post mortem examination of the case was carried out as per the standard procedure mentioned in the "Autopsy diagnosis and technique" by Otto Saphire. Blood and viscera were sent for chemical analysis in suspected cases of poisoning. Various iatrogenic cutaneous artefacts were recorded. Results thus obtained were subjected to statistical analysis. P value less than 0.05 was considered significant. 


\section{Results}

Table 1: Distribution of patients

\begin{tabular}{|c|c|c|}
\hline \multicolumn{3}{|c|}{ Total- 152 } \\
\hline Gender & Males & Females \\
\hline Number & 82 & 70 \\
\hline
\end{tabular}

Table 1, graph 1 shows that out of 152 patients, males were

82 and females were 70.

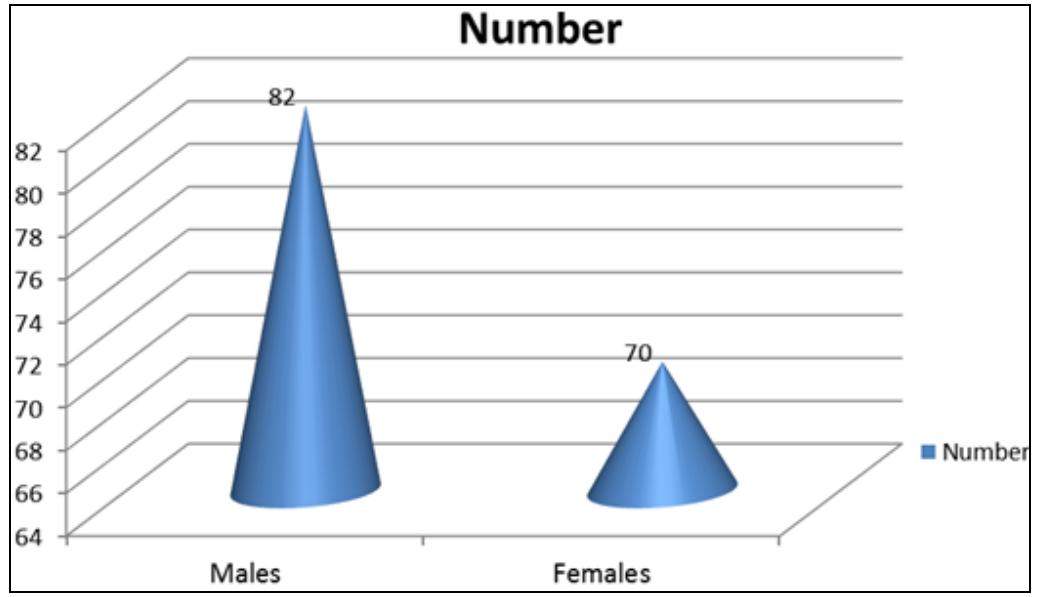

Graph 1: Distribution of patients

Table 2: Artefacts recorded during post mortem

\begin{tabular}{|c|c|c|}
\hline Artefacts & Number & P value \\
\hline IV line mark & 4 & \\
\hline Defibrillator burn mark & 12 & \\
\hline Abdominal drainage & 3 & \multirow{2}{*}{0.01} \\
\hline Intercoastal drainage & 2 & \\
\hline CVP line mark & 17 & \\
\hline Venesection & 10 \\
\hline Fasciotomy wound & 2 \\
\hline Tracheostomy wound & 3 & \\
\hline
\end{tabular}

Table II shows that common artefacts were iv line mark in 4 , defibrillator burn mark in 12, abdominal drainage in 3 , intercoastal drainage in 2, CVP line mark in venesection in 10, fasciotomy wound in 2 and tracheostomy wound in 3 cases. The difference was significant $(\mathrm{P}<0.05)$.

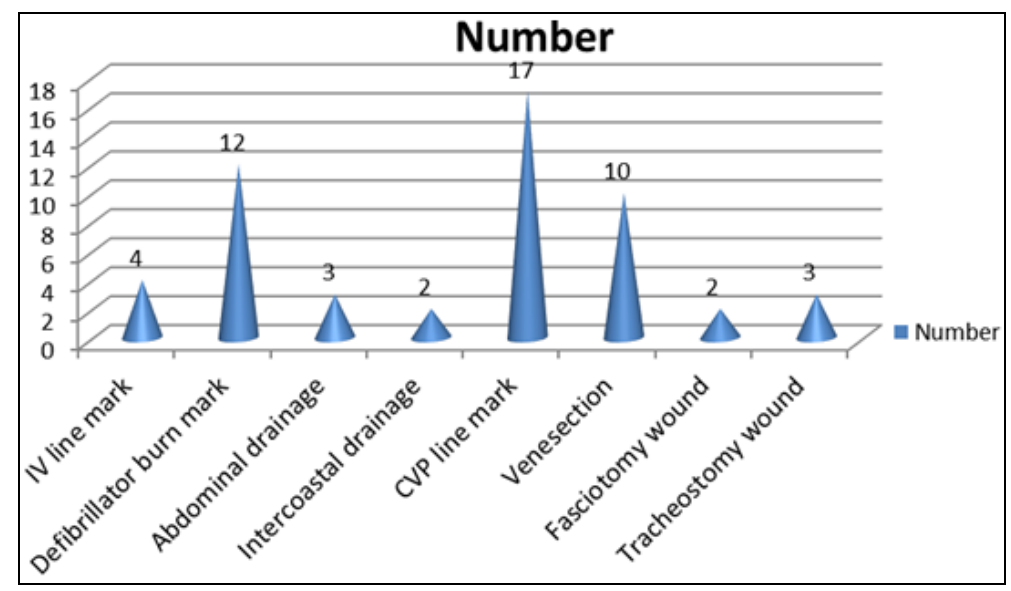

Graph 2: Artefacts recorded during post mortem

\section{Discussion}

One of the most difficult and sensitive issues in medicolegal pathology is the autopsy investigation of a death which may be associated with medical intervention. There is a wide spectrum of these cases, ranging from surgical and anaesthetic mishaps to drug reactions or the failure to offer the correct (or any) treatment ${ }^{[5]}$. Before further discussion of the subject, it should be appreciated that the death may be due to causes quite unrelated to medical intervention, even if due to diagnostic or therapeutic procedures (or their omission), the death may have been entirely unavoidable, i.e. purely accidental and the death may have been due to medical negligence ${ }^{[6]}$. The present study was conducted to assess iatrogenic artefacts during autopsy. 
In present study, out of 152 patients, males were 82 and females were 70 . Parate et al. ${ }^{[7]}$ conducted a study to study the pattern of iatrogenic cutaneous artefacts encountered during autopsy and to ascertain the relationship of iatrogenic cutaneous artefacts to sex of the deceased if any. Data was collected by detailed questionnaire, focusing on the history furnished by the police in requisition form and inquest report, by the relatives and hospital records. Iatrogenic cutaneous artefact was present in $58.13 \%$ cases. Out of these $34.38 \%$ were males and $23.75 \%$ were females. Most common cutaneous artefact was intravenous injection line mark mimicking like contusion. It was present in $45.00 \%$ cases. Defibrillator burn artefact was present in $12.80 \%$ cases. Chest abrasion/contusion was present in $13.13 \%$ cases. Iatrogenic cutaneous artefacts were found to be independent and there is no relation between these artefacts and sex of the deceased.

We found that common artefacts were iv line mark in 4, defibrillator burn mark in 12, abdominal drainage in 3 , intercoastal drainage in 2, CVP line mark in 17 , venesection in 10, fasciotomy wound in 2 and tracheostomy wound in 3 cases.

Before the autopsy, the pathologist should obtain and read all available clinical records and notes ${ }^{[8]}$. To carry out an autopsy "blind" is often a waste of time. As well as studying the clinical notes, it is essential to discuss the case with the relevant clinicians, either before and/or during the autopsy. The clinicians should be present at the autopsy wherever possible-preferably the senior clinicians in clinical charge of the case. Even if unable or unwilling to attend, they must always be invited, so that they cannot later complain that the post-mortem examination was done without their knowledge ${ }^{[9]}$. It is not satisfactory if only a junior doctor attends, such as a house-officer, who often claims to know little or nothing about the case. Where there are complaints by the family and the possibility of allegations of negligence, the autopsy should be carried out by a senior pathologist, as there may be later legal complications, which require expert interpretation and may lead to an appearance in court. If a junior pathologist actually performs the autopsy, amore senior colleague should be present to offer support and advice and to review the findings ${ }^{[10]}$.

\section{Conclusion}

Authors found that common artefacts were IV line mark, defibrillator burn mark, abdominal drainage, intercoastal drainage, CVP line mark, venesection, fasciotomy wound and tracheostomy wound.

\section{References}

1. Knight B. The Coroner's Autopsy. Edinburgh: ChurchillLivingstone, 1983, 1-42.

2. Knight B. Legal Aspects of Medical Practice. 4th ed. Edinburgh: Churchill-Livingstone, 1987, 53-112.

3. Knight B. Forensic Pathology. London: Edward Arnold, 1991, 1-46.

4. Ludwig J. Current Methods of Autopsy Practice. Philadelphia: Saunders WB, 1979.

5. Gardner AN. Aspiration of food and vomit. J Med. 1958; 27:227-42.

6. Knight B. The significance of gastric contents in the air passages. Forensic Sci Int. 1976; 14:398-402.

7. Parate SV, Samanta AK, Harish S, Chandra G. Iatrogenic cutaneous artefacts encountered during autopsy. Indian Journal of Forensic and Community Medicine. 2017; 4(2):121-3.

8. Dolinak David, Matshes Evan W, Lew Emma O. Forensic pathology principles and practice. Oxford: Elsevier, 2005, 317.

9. Otto Saphire. Autopsy diagnosis and technic. 4th ed. Illinois: Hoeber Harperm, 1965, 17-30.

10. Krischer JP, Fine EG, Davis JH, Nagel EL. Complications of cardiac resuscitation. Chest. 1987; 92:287-291. 